\title{
SOCIEDADE DO TRABALHO E A VIDA DETERMINADA PELA IDENTIDADE DE GÊNERO: por uma perspectiva materialista da condição socioeconômica da comunidade trans ${ }^{1}$
}

\author{
Eduardo Sá Barreto² \\ Igor Lira ${ }^{3}$
}

\begin{abstract}
Resumo:
O artigo propõe uma reinterpretação dos desafios socioeconômicos enfrentados pela comunidade transgênera. Para tal, explora-se os limites da categoria transgênero, partindo de insights do pensamento feminista. Em seguida, articula-se tal entendimento em uma reflexão acerca das implicações de encontrar-se excluído do mercado de trabalho. Disso, desdobram-se três frentes de argumentação: uma crítica à própria sociedade do trabalho; uma discussão quanto às possibilidades de realização das demandas da comunidade trans; e a demonstração da necessidade de que elas assumam caráter anticapitalista.
\end{abstract}

Palavras-chave: transgênero; trabalho; emancipação

\begin{abstract}
:
The article proposes a reinterpretation of the socioeconomic challenges faced by the trans-gender community. For this, the limits of the trans-gender category are explored, starting from insights of the feminist thought. Next, this understanding is articulated in a reflection on the implications of being excluded from the labor market. From this, three fronts of argument unfold: a critique of the labor society itself; a discussion about the possibilities of realizing the demands of the trans-gender community; and the demonstration of the need for them to assume an anti-capitalist character.
\end{abstract}

Keywords: trans-gender; labor; emancipation

\footnotetext{
${ }^{1}$ DOI: https://doi.org/10.22409/tn.15i28.p9639

${ }^{2}$ Professor Adjunto do Departamento de Economia da UFJF e pesquisador associado ao NIEPMarx (UFF). Contato: eduardo.barreto@ufjf.edu.br

${ }^{3}$ Bacharel em Economia pela UFJF. Contato: igorlira.jf@hotmail.com
} 


\section{Introdução}

Não é preciso muito esforço para reconhecer que as pessoas transgêneras se deparam, em geral, com desafios de ordem socioeconômica que excedem em muito quaisquer dificuldades de foro íntimo que esses indivíduos possam vir a enfrentar por se identificar de forma não aderente ao que é admitido como normal. A forma como a comunidade trans se posiciona, de modo mais ou menos organizado, diante desses desafios é o objeto de nossa reflexão neste artigo.

Há, nesse posicionamento (que não é de todo homogêneo), uma série de aspirações difusas que, no entanto, podem ser resumidas no objetivo bastante abrangente de aceitação (assimilação, incorporação) social. Colocado nesses termos, trata-se, obviamente, de uma meta legítima. Sua legitimidade, contudo, não garante sua realização. Por isso, são as questões relacionadas às possibilidades de realização que serão aqui discutidas.

Para isso, é fecundo trabalhar com as seguintes mediações que, em nosso juízo, informam a maneira como as reivindicações são formuladas: a aceitação social como chave para um acesso mais amplo e qualitativamente melhor ao mercado de trabalho; e o acesso ampliado ao mercado de trabalho como chave para a autonomia individual e coletiva.

Dividimos o texto em quatro seções. Na primeira, exploramos a categoria transgênero, buscando delinear os limites mínimos dentro dos quais ela faz sentido. Com isso, pretendemos não apenas oferecer elementos capazes de habilitar o discurso e a prática da comunidade trans, mas também iluminar elementos que a fragilizam. Na segunda, debatemos a centralidade do trabalho na sociedade capitalista e as implicações de encontrar-se excluído do mercado de trabalho. Na terceira, direcionamos essa análise para construir o argumento de que não há esperança em superar tal exclusão (em qualquer grau significativo), a não ser superando a própria lógica do capital. A última seção conclui. 


\section{Questões preliminares: pontes com o feminismo (possibilidadese limites)}

Embora o título desta seção declare uma pretensão em dialogar com "o feminismo", é necessário reconhecer, de imediato, que "feminismo" é um campo significativamente heterogêneo e que, por isso, deve estar claro que não constitui objetivo do artigo contemplar todos (nem mesmo os principais) os matizes do pensamento feminista. A despeito desta limitação de partida, contudo, sustentamos que é possível mapear alguns elementos cruciais para a adequada compreensão de nossa temática. Cruciais não porque o pensamento feminista trate da condição da mulher na sociedade contemporânea, mas porque trata de uma condição de opressão determinada pelo gênero.

Tampouco pretendemos alcançar uma elaboração mais adequada, precisa, correta da categoria gênero, tão importante neste debate. Butler (2007), Haraway (1991) e Beauvoir (1970) ilustram o quão controversa e pantanosa pode ser esta seara. Adota-se aqui, portanto, uma estratégia alternativa. Pretende-se, nesta seção preliminar, estabelecer os limites mínimos dentro dos quais a categoria gênero confere sentido à categoria transgênero.

Segundo Haraway (1991, p. 133), o "paradigma da identidade de gênero foi uma versão funcionalista e essencializante do insight de Simone de Beauvoir, nos anos 1940, de que não se nasce mulher". Comecemos então por Beauvoir, que além do enunciado acima, também afirma, por exemplo, que elas "são mulheres em virtude de sua estrutura fisiológica" e que a "divisão dos sexos é, com efeito, um dado biológico e não um momento da história humana" (BEAUVOIR, 1970, pp. 12-3). Como conciliar essas ideias, aparentemente inconciliáveis? Basicamente, de duas formas: primeiro, demonstrando que a existência social possui uma base natural ineliminável, da qual se afasta à medida que se desenvolve e da qual não pode ser mecanicamente deduzida; segundo, que a despeito do caráter insuprimível da base natural, emergem no seio do ser social categorias puramente sociais, mas que nem por isso devem ser entendidas como fenômenos puramente subjetivos.

Colocando a questão ainda em outros termos, podemos contornar muitas das dificuldades observadas nos debates clássicos se evitarmos sua 
frequente negligência com questões ontológicas e, mais especificamente, com a natureza própria do tecido social. Para tal, duas categorias são fundamentais: emergência e poderes emergentes.

A primeira diz respeito à relação entre dois entes, digamos $X$ e $Y$, de tal forma que $Y$ surja de $X$, mas sem ser dedutível de $X$. $O$ que temos aqui é a afirmação de que $Y$ é irredutível a $X$; ou seja, a afirmação de que $Y$ não pode ser conhecido, explicado, descrito apenas por meio de categorias deduzidas a partir de X. Basicamente, temos na categoria de emergência a chave para escapar de ontologias estruturalistas ou atomistas da sociedade. Mas deixemos a ideia menos abstrata.

Lukács (2012) é um dos principais pensadores marxistas a tratar explicitamente de questões ontológicas. Segundo o autor, é possível afirmar que a vida, tal como a conhecemos, apresenta três níveis de ser: inorgânico, orgânico e social. O orgânico emerge do inorgânico, mas é irredutível a ele; o social emerge de ambos (que Lukács chama de ser natural), mas é irredutível a eles.

O que significa o caráter irredutível, neste caso? Que embora cada um desses níveis de ser surja da emergência a partir de um outro, desenvolve categorias e causalidades próprias (que chamamos acima de poderes emergentes), que inexistem no outro. Contudo, é fundamental reconhecer que tais causalidades, embora próprias, nunca podem suprimir as causalidades/legalidades do plano que the deu origem, permanecendo sempre existencial e causalmente subordinadas a ele ${ }^{3}$.

As implicações dessa ideia simples para o nosso tema são profundas. Já temos elementos para sustentar que não apenas o ser social emerge do ser natural, mas também que, à medida que se desenvolve, surgem categorias e legalidades que the são próprias (exclusivas). Mais que isso, estas surgem como resultado/síntese não-intencional de agires intencionais, como fruto de escolhas substantivas de indivíduos agindo socialmente (LAWSON, 1997). Essa conclusão poderia nos conduzir a uma sobrevalorização da subjetividade.

\footnotetext{
${ }^{3} \mathrm{~A}$ ideia de subordinação pode parecer controversa, porém de forma alguma a usamos aqui em um sentido de determinação, o que ficará mais claro na sequência.
}

TrabalhoNecessario - www.uff.br/trabalhonecessario; Ano 15, №28/2017 
A discussão a respeito da emergência, todavia, impede este equívoco, já que deixa claro que tal liberdade atua necessariamente em um espaço de possibilidades que antecede a escolha e o agir. Em outros termos, como todo agir intencional é agir em sociedade, as estruturas e legalidades próprias da sociedade (e também aquelas próprias do ser natural) sempre habilitam, limitam, constrangem, impedem, dificultam, facilitam etc. 0 agir.

Analogamente, como pressupostos ontológicos do ser social, o ser inorgânico e o ser orgânico delimitam o espaço de possibilidades para o ser social e os indivíduos. Por mais que nossa espécie se distinga de todas as demais por sistematicamente trazer à realidade coisas não-naturais, trata-se sempre da efetivação de possibilidades previamente latentes neste espaço de possibilidades natural. Desde uma rústica mesa de madeira até o rastreamento via GPS e as viagens espaciais, nada disso existiria na ausência da intervenção humana. No entanto, nenhum desses exemplos envolvem a anulação, violação ou superação das legalidades naturais; envolvem simplesmente a sua adequada mobilização para a realização de finalidades postas.

A partir desse raciocínio, temos um quadro mais rico para tratar da relação objetividade-subjetividade. Quando, por um lado, reconhecemos que o ser natural e o ser social impõem resistências ao agir intencional, escapamos da supervalorização da subjetividade, de um construtivismo de caráter voluntarista ou idealista. Quando, por outro, admitimos que emergência e subordinação não negam a existência de categorias tipicamente sociais, escapamos da supervalorização da objetividade, de um naturalismo de corte biológico ou químico.

Não é por simples acaso que pretendemos rejeitar tais posições. Em primeiro lugar, suas variadas gradações povoam o debate no campo do pensamento feminista. Em segundo lugar, elas - na maioria das vezes inadvertidamente - inviabilizam ora qualquer concepção de um indivíduo trans, ora a legitimidade (ou o peso) de suas reivindicações. Tais posições nada mais são do que polos opostos de um mesmo conjunto de incompreensões a respeito de nossa existência como seres naturais/biológicos e como seres

TrabalhoNecessario - www.uff.br/trabalhonecessario; Ano 15, №28/2017 
sociais.

Em nosso juízo, a afirmação contundente de Beauvoir de que não se nasce mulher deve ser reinterpretada, especialmente para discutir a condição social da comunidade transgênera. A própria autora ilustra exaustivamente que embora as determinações sociais desempenhem um papel fundamental e central na conformação do gênero, há uma base natural que permanece ineliminável. $E$ ainda que se possa falar de um desenvolvimento puramente social da categoria mulher ou gênero, seria inadequado daí concluir que o caráter social da categoria gênero pode ou deve ser entendido como puramente subjetivo. Não se deve entender puramente social como algo que é simplesmente fruto da livre construção subjetiva (individual ou coletiva) ou, pior, da imaginação. O mesmo insight pode ser encontrado no tratamento inicial de Marx (2013[1867]) da categoria valor, por exemplo. Ali, o autor explicitamente demonstra que o valor não possui qualquer existência física ou química, pois existe apenas no interior de relações sociais. Nem por isso deixa de ter existência objetiva, posto que rege e condiciona tais relações.

Embora possa parecer à primeira vista, nossa insistência em tais nuances não é motivada por algum tipo de preciosismo academicista e diletante. Dissemos no início da seção que pretendíamos, neste momento inicial, explorar os limites da categoria transgênero. ${ }^{4}$ Daquilo que foi discutido até aqui, é possível afirmar que, para que a categoria transgênero seja dotada sentido, é necessário que gênero seja, por um lado, algo relativamente fluido, e, por outro, algo relativamente determinado pela corporalidade física. Vejamos porquê.

Se gênero fosse algo completamente fluido (ou seja, perfeitamente sensível à subjetividade individual), por que reivindicar-se mulher ou homem? Há inúmeras respostas possíveis e cada indivíduo transgênero certamente terá a sua versão pessoal. Mas é crucial perceber que a ideia de fluidez completa do gênero também confere sentido a outras variedades de concepções e motivações: apenas para citar dois exemplos assombrosos, as ideias de "cura"

\footnotetext{
${ }^{4}$ Esperamos também que fique claro que as concepções correntes mais frequentes se situam fora desses limites.
}

TrabalhoNecessario - www.uff.br/trabalhonecessario; Ano 15, №28/2017 
pela educação ou de conformidade (digamos, cis normativa) imposta por lei. A noção de que gênero é algo completamente fluido carimba, talvez sem perceber, um selo de "escolha livre" sobre a condição transgênera, o que certamente abre um flanco considerável para que se creia ser possível impor alguma escolha específica, supostamente mais desejável ou aceitável, sobre o indivíduo.

Para além desse tipo de preocupação (afinal de contas, uma ideia não necessariamente deixa de ser correta ou verdadeira apenas porque ela tem implicações perigosas ou indesejáveis), é possível mostrar que a fluidez completa simplesmente não existe. Basta reconhecer que o indivíduo trans com frequência se submete a intervenções cirúrgicas e tratamentos hormonais longos, agressivos e dolorosos com o intuito de adequar seu corpo à sua identidade de gênero. A corporalidade impõe resistência, portanto, à identidade.

Se, alternativamente, o gênero fosse completamente determinado pela constituição corporal, inexistiria a possibilidade de divergência entre a existência física do indivíduo e sua identidade de gênero. Pode parecer que uma concepção como essa jamais circularia em ambientes em que pessoas se dedicam a refletir sobre a condição das pessoas transgêneras. Mas estendendo um pouco a ideia anterior para uma concepção de inescapabilidade do ser natural, percebemos que, curiosamente, este não é o caso. Com frequência, a identidade de gênero é entendida como determinada quimicamente (balanços hormonais etc.), inadvertidamente conferindo sentido a concepções que, por exemplo, viessem a defender a "cura" por meio de tratamentos hormonais.

Temos então que, de um lado, o entendimento naturalista colapsa o ser social no ser natural, tomando as categorias homem e mulher como imediatamente dadas na natureza, como idênticas a macho e fêmea, esvaziando completamente de sentido a categoria trans. De outro, a versão mais extrema da concepção construtivista desvincula radicalmente a existência social da natural, ancorando gênero numa espécie de subjetividade coletiva moldada (de maneira mais ou menos intencional) a serviço de estruturas 
sociais opressoras. Mais importante, tais estruturas opressoras poderiam ser subvertidas exclusivamente neste mesmo plano, o da subjetividade (p.ex., se construído um entendimento correto, um enlightenment, suficientemente amplo). Como procuramos apontar, porém, o postulado de uma perfeita maleabilidade do tecido social pode tanto ser colocado a serviço de reivindicações da comunidade transgênera como a serviço de concepções cis normativas.

\section{Centralidade da identidade de gênero e o mundo do trabalho}

Ao contrário da maior parte da população, a comunidade trans tem, em geral, a totalidade de sua vida (sociabilidade) determinada por sua identidade de gênero. Reside aí um traço dramático da condição transgênera: a essas pessoas é frequentemente negado - em geral a priori, precisamente em virtude de serem pessoas trans - 0 acesso a oportunidades de trabalho e renda. As implicações mais diretamente reconhecíveis dessa exclusão são o ostracismo social e o recurso a atividades marginalizadas, como a prostituição. Por isso, é comum associar esses resultados às causas mais superficiais de tal exclusão: a transfobia, para usar um termo sintético e corrente. Formulado o diagnóstico nesses termos, dificilmente a solução poderia ser outra: superar a transfobia.

A despeito de esse ser, em nosso juízo, um objetivo evidentemente desejável, pretendemos perseguir a questão um pouco mais além. Há, entre os fatos inegáveis da transfobia e do ostracismo das pessoas trans, uma cadeia mais complexa de mediações. Para encontrá-la, é fecundo retornar à discussão do fetichismo da mercadoria.

Já no primeiro capítulo de O Capital, Marx demonstra como, na sociedade capitalista, os traços sociais da atividade humana reaparecem como qualidades objetivas do produto desta atividade. Primeiro, mostra como a dimensão comum entre as diversas formas de trabalho se exterioriza como atributo da mercadoria, assume a forma de "igual objetividade de valor dos produtos do trabalho". Em seguida, como a medida do dispêndio de trabalho TrabalhoNecessario - www.uff.br/trabalhonecessario; Ano 15, №28/2017 
por meio de sua duração se exterioriza como medida daquele atributo, figurando como grandeza de valor da mercadoria. Finalmente, como a relação social entre os trabalhos se exterioriza na relação entre mercadorias, i.e. como a própria divisão social do trabalho se processa e se confirma a posteriori, por meio de relações sociais entre os produtos do trabalho.

O uso do termo fetichismo por Marx simplesmente sintetiza esse triplo processo de exteriorização, distintivo do capitalismo. Distintivo desta sociedade porque os objetos de uso, produtos da atividade humana, assumem universalmente a forma mercadoria apenas quando são produto de trabalhos privados, mutuamente autônomos (realizados independentemente uns dos outros). Assim estruturado o trabalho social total, como soma tardia dos trabalhos privados, os produtores só travam efetivamente contato social entre seus trabalhos por meio da troca de mercadorias. Uma primeira implicação substantiva para o tema aqui tratado é que os traços sociais da atividade produtiva só aparecem no âmbito da troca. Em outros termos, os trabalhos privados só atuam de fato como elementos do trabalho social total por intermédio do mercado.

Não pretendemos simplesmente reprisar o conhecido enunciado marxiano que aponta para as relações reificadas (coisificadas) entre pessoas e as sociais entre coisas. Há algo mais a se retirar deste raciocínio. De tudo o que foi dito, é possível afirmar que o acesso dos agentes da troca à riqueza social, às condições materiais de vida, é determinado pelo quanto de produtos alheios eles obtêm em troca por seu próprio, ou seja, em que proporções os produtos são trocados. Contudo, posto que tais proporções são determinadas pelo tempo de trabalho socialmente necessário (isto é, por condições sociais de produção nas quais o produtor individual desempenha apenas papel atomizado), variam constantemente, independente da vontade, previsão ou ação daqueles que realizam a troca. O movimento social dos produtos do trabalho constitui-se, portanto, como um movimento à margem dos produtores; um movimento sob cujo controle se encontram, e não o contrário.

Além do próprio Marx, autores como Lukács (2013), Postone (2003) e 
Duayer \& Medeiros (2008) já sublinharam em detalhe esta implicação profunda da natureza fetichista da sociedade capitalista. Para os propósitos deste trabalho, importa reforçar o seguinte ponto: apenas participam deste movimento estranhado os proprietários de mercadoria, uma vez que a mediação realmente incontornável entre indivíduo e riqueza social é efetivada pela troca. E aos que nada possuem a não ser sua própria força de trabalho, não resta outra alternativa senão vendê-la. Por isso, excluir todo um grupo de pessoas do mundo do trabalho implica excluí-las, em grande medida, da própria sociedade 5 . Por isso, as demandas por assimilação da comunidade trans no mercado de trabalho, que em parte animam a presente reflexão, são carregadas de uma urgência inegável.

Muitos pensadores (marxistas ou não, conscientemente ou não) já intuíram esse traço de nossa sociedade. Todavia, este reconhecimento, não raro, compõe interpretações em muitos sentidos a-históricas, que projetam a centralidade do trabalho como categoria mediadora fundamental da existência social para a totalidade da experiência humana. No caso dos marxistas, isso é particularmente problemático quando se desdobra em uma crítica do capitalismo desde uma perspectiva do trabalho ${ }^{6}$. Em poucas palavras, uma crítica que se limita a rejeitar os "mecanismos de distribuição" de riqueza no capitalismo e seus efeitos deploráveis e injustos sobre a classe trabalhadora.

Para que fique claro, o problema neste tipo de interpretação não é que tais efeitos não sejam de fato deploráveis e injustos. O problema é que se parte de uma equivocada desvinculação entre os ditos "mecanismos de distribuição" e a determinação do valor pelo tempo de trabalho socialmente necessário; determinação esta que se encontra na raiz da interpretação marxiana da especificidade histórica da sociedade capitalista e que Postone (2003) utiliza habilmente para demonstrar que apenas nesta quadra histórica o trabalho ocupa irremediavelmente o centro da vida em sociedade. ${ }^{7}$

5 "Somente a participação na esfera do trabalho dá acesso a uma existência pública e a um papel de sujeito" (JAPPE, 2013).

${ }^{6}$ Vale frisar que este não é o caso dos autores mencionados no parágrafo anterior.

7 É importante deixar claro que rejeitar uma centralidade trans-histórica do trabalho não corresponde a rejeitar a prioridade ontológica do trabalho na existência social, tal como

TrabalhoNecessario - www.uff.br/trabalhonecessario; Ano 15, №28/2017 
Tal desvinculação, por sua vez, além de ser míope em relação à dinâmica fetichista e estranhada produzida pela lógica própria do capital, frequentemente se converte em posturas defensoras (ou mesmo apologéticas) do mundo do trabalho. Posturas que, ao fim e ao cabo, almejam tão somente alçar a classe trabalhadora a uma posição mais privilegiada. No caso que aqui tratamos, tal tipo de posicionamento pode inclusive se converter em defesas apaixonas da incorporação irrestrita da comunidade transgênera a este mundo, da garantia do afamado "direito ao trabalho" ${ }^{8}$. Seguindo Postone (2003, p. 369), porém, é possível indicar que

a extensão dos princípios universalísticos da sociedade burguesa a segmentos mais amplos da população - isto é, a realização desses princípios - que foi, em parte, efetivada por movimentos da classe trabalhadora, assim como por aqueles elementos de movimentos das mulheres e movimentos de minorias que lutaram por direitos iguais, não deve ser entendida como um desenvolvimento que aponta para além da sociedade capitalista. Embora tais movimentos tenham democratizado enormemente a sociedade capitalista, a forma de universalidade que ajudaram a constituir é uma que [...] permanece presa à forma-valor de mediação.

Por ora, trabalhemos a conclusão mais direta desta passagem: a expressão/manifestação prática das aspirações aqui tratadas não possui natureza anticapitalista, por mais que tragam resultados que podem ser considerados como avanços. Talvez não pareça muito a título de conclusão, já que certamente não é pré-requisito de qualquer tipo de mobilização coletiva a presença de conteúdo revolucionário. Contudo, como deve ficar claro adiante, o exame rigoroso das possibilidades de realização dos anseios de assimilação naturalmente conduz à necessidade de demonstrar que a mobilização da comunidade transgênera deve assumir consciência e caráter anticapitalista, se realmente pretende ser emancipatória.

apontada por Lukács (2013).

8 Artigo 23 da Declaração Universal dos Direitos Humanos. Disponível em: http://unesdoc.unesco.org/. Acesso em 1 de abril de 2017.

TrabalhoNecessario - www.uff.br/trabalhonecessario; Ano 15, №28/2017 


\section{A luta emancipatória: assimilação ou ruptura?}

Em sua crítica à pulverização contemporânea das lutas sociais, Carcanholo e Baruco (2010) advertem que é preciso não desdobrar a correta identificação da ausência de traços revolucionários em uma completa rejeição do tipo de mobilização sob análise. As razões para isso podem também ser retiradas de nossa discussão anterior: a realidade social em que vivemos é de fato estruturada e organizada em torno do trabalho, e ser excluído do rol dos "empregáveis" é ter negadas as condições mais básicas de sobrevivência nesta sociedade. É fundamental, portanto, que a crítica às limitações e insuficiências das demandas da comunidade trans venha combinada a uma intransigente rejeição da conservação do status quo a que ela é submetida.

Nesse mesmo sentido, por exemplo, Jappe (2013, p. 99) ressalta que

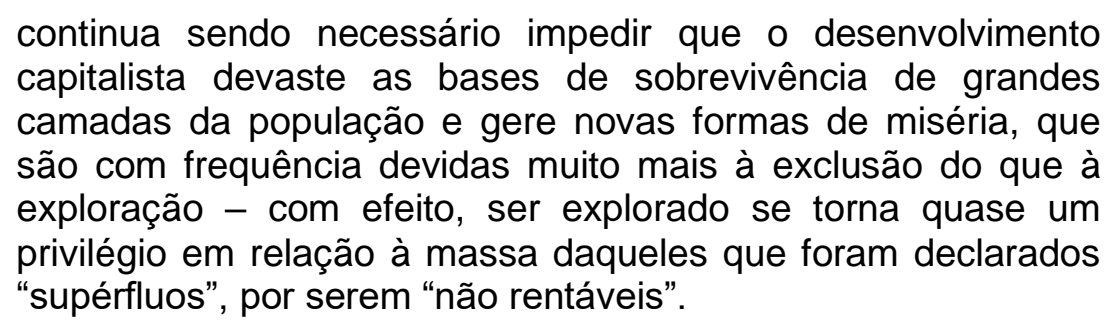

Esse trecho ilustra vividamente que a luta por autonomia, dignidade etc., quando predicada a (e circunscrita por) uma ascensão à condição de trabalhador, não pode ser emancipatória, posto que equivale simplesmente ascender à condição de explorado (mesmo que saindo de uma condição ainda pior). A luta por assimilação pode vir a vencer preconceitos estritamente relacionados a condição de gênero, mas não cria as condições de possibilidade para uma vida digna à comunidade como um todo. Neste mesmo registro de luta, vencidos os desafios via gênero, permaneceriam empecilhos via raça, nacionalidade etc.

Conforme sustentam Carcanholo e Baruco (2010), o capitalismo é indiferente a diferenças extraeconômicas. A lógica do sistema pode, portanto, conviver indefinidamente com a exclusão social de certos grupos, mesmo que o "certo grupo" possa nem sempre ser o mesmo. Pode também, por outro lado, operar uma incorporação relativamente extensa, mas que tende a ser homogeneizante. Por exemplo, a mulher, em geral, é tanto mais assimilada ao TrabalhoNecessario - www.uff.br/trabalhonecessario; Ano 15, №28/2017 
mercado de trabalho - ocupando posições mais relevantes e de prestígio e com maiores níveis de remuneração - quanto mais ela for capaz de reproduzir traços de conduta geralmente associados aos homens, ocupantes tradicionais dessas posições.

Tampouco faz sentido pensar em realizar os anseios das variadas microcontestações um a um até a realização completa de uma sociedade emancipada, pois o pressuposto lógico de mobilizações que se organizam em torno de questões identitárias é exatamente a suposição (consciente ou não) da ausência de um elo que as articule, ou que torne sua origem e legitimidade conjuntamente inteligíveis no interior de um ordenamento social geral (KOHAN, 2007).

Há, neste entendimento, um discernível componente pós-moderno, mais precisamente o reconhecimento da natureza difusa do poder na realidade social em que vivemos (CARCANHOLO e BARUCO, 2010). Falta, contudo, um elemento crucial neste reconhecimento, de inspiração foucaultiana: o poder é difuso, transversal e ninguém o centraliza substantivamente; mas ao mesmo tempo, ninguém o detém, ele é impessoal e abstrato. Se lembrarmos que a reflexão acerca do fetichismo, na segunda seção, concluiu que o movimento social dos produtos da atividade humana escapa ao controle dos indivíduos e os subordina, podemos reformular essa passagem e dizer que o poder é impessoal, abstrato e totalizante. Kohan (2007, p. 15) ilustra este ponto concretamente:

Paradoxalmente, ainda que na literatura filosófica acadêmica dos anos 70, 80 e 90 se tenha produzido o festival do fragmento e o relato micro [...], na vida econômica, política e militar a ordem social do capitalismo tomava exatamente um sentido inverso. Ainda que já desde suas origens o capitalismo constitua um sistema mundial em constante expansão [...], nunca antes a história assistiu a semelhante onda expansiva das relações sociais mediadas pelo dinheiro e o capital.

O que justifica então um enfrentamento totalizante? Sua necessidade é um simples postulado? Não! O que justifica é que o próprio metabolismo socioeconômico é totalizante, e seus efeitos parciais são, em geral, predicados à lógica/dinâmica da totalidade. A categoria da totalidade é fundamental, 
portanto, não apenas para a análise/investigação da realidade, mas também para sua transformação.

O trecho citado acima dá a pista para aprofundar a questão. As décadas do pós-guerra marcam o início deste momento sem precedentes de expansão das relações sociais mediadas pelo capital. No centro dos processos transformadores do período, uma inflexão dramática nas possibilidades de automação da produção, proporcionada pela revolução da microeletrônica. Evidentemente, a contraparte de tais possibilidades de automação é simplesmente a possibilidade de prescindir crescentemente do trabalho numa variedade sempre crescente de processos produtivos. Uma primeira implicação de tais transformações, sustenta Postone (2003, pp. 371-2), "é a crescente contradição entre necessidade e não-necessidade do trabalho criador de valor, [...] que precisamente aquilo que constitui a formação social e é a ela necessário - o trabalho atuando como atividade de mediação social - torna-se crescentemente desnecessário em termos do potencial do que ele constitui".

O potencial ao qual Postone se refere aqui é o das forças produtivas, o potencial extraordinário e crescente de produzir riqueza material com exigências cada vez menores (pelo menos em termos relativos) de trabalho. $O$ autor prossegue no argumento para demonstrar que essa possibilidade crescente de converter tempo de trabalho necessário em tempo livre não pode ser realizada na sociedade capitalista. Para o capital, afirma, é imperativo converter qualquer redução do tempo de trabalho necessário em tempo de trabalho excedente; ou seja, tempo de trabalho criador de mais-valor. Aqui nos interessa, contudo, outro ponto que pode ser combinado ao raciocínio de Postone.

Avaliando as mesmas transformações históricas, que coincidem com a dissolução da assim chamada Era de Ouro do capitalismo, Kurz (2014) aponta para o esgotamento histórico de uma engrenagem fundamental: o mecanismo que até então havia garantido - via ampliação do escopo e da escala de atuação do capital - que a massa de trabalho vivo absorvida pelo capital permanecesse crescente, mesmo diante do declínio da participação relativa desse trabalho. Conforme demonstrado por Marx (e inúmeros outros marxistas), 
a concorrência entre os capitais impele a sociedade à sistemática elevação das forças produtivas. A já mencionada revolução da microeletrônica é um dos momentos em que essa tendência se processa em um salto abrupto e pronunciado de produtividade, eficiência etc., trazendo consigo (pela primeira vez na história) a possibilidade técnica de generalização de processos produtivos automatizados.

Não chega a ser novidade a conclusão de que o aumento das forças produtivas diminui (relativamente) a capacidade do capital de empregar força de trabalho. Até mesmo Ricardo (1996[1817]), economista do início do século XIX, já reconhecia tal implicação. A novidade qualitativa deste salto, dirá Kurz, é que as novas formas emergentes de produzir prescindem do trabalho em tal escala e velocidade que a capacidade do capital de empregar trabalho vivo decresce não apenas em termos relativos, mas em termos absolutos. Isso porque mesmo os novos ramos de atividade passam a já "nascer" praticamente incapazes de absorver trabalho. Nas palavras do próprio Kurz (2014, p. 267):

\begin{abstract}
na terceira Revolução Industrial da microeletrônica ocorreu [...] uma reviravolta. Manifestou-se algo que desde sempre tinha sido concebível em termos lógicos, a saber, o aumento da força produtiva a uma tal escala que a transição para a produção em massa, nos produtos novos, já não requer uma quantidade suficiente de força de trabalho adicional para ser capaz de compensar a diminuição do dispêndio de trabalho por mercadoria. [...] a entrada de novos produtos já de si pobres em trabalho - e que o são cada vez mais - na produção em massa e no consumo de massas desalavanca o mecanismo de compensação em vigor e faz parar o movimento de expansão interna do mais-valor para tal necessário.
\end{abstract}

Como é possível perceber ao fim do trecho, a objeto da análise de Kurz é a produção de mais-valor (e os obstáculos criados pelo próprio capital a essa produção). Mas o argumento possui implicações concretas que nos interessam aqui. O raciocínio acima reproduzido é capaz fornecer uma interpretação teórica do desemprego endêmico como uma tendência imanente da sociedade capitalista e irreversível no interior de seus parâmetros próprios de reprodução; ou seja, não como uma ocorrência conjuntural, eventualmente provocada por políticas econômicas, sociais, educacionais equivocadas etc. Para isso, basta reconhecer, por um lado, a tendência imanente e irrefreável ao avanço das TrabalhoNecessario - www.uff.br/trabalhonecessario; Ano 15, №28/2017 
forças produtivas e, por outro, que as alternativas para empregar a força de trabalho tornada relativamente supérflua tendem a se exaurir.

\section{Considerações finais}

Por tudo isso, é seguro concluir que o capitalismo atual é uma sociedade com capacidade rarefeita para empregar trabalho. De imediato, não parece uma descoberta significativa, já que qualquer observador atento seria capaz de afirmar algo semelhante a respeito de nossa realidade presente. $O$ que de fato traz uma implicação superlativa para as aspirações de grupos minoritários excluídos é a afirmação de que essa capacidade é crescentemente rarefeita e, no capitalismo, irreversível.

Em outras palavras, justamente no momento em que certos grupos alcançam visibilidade suficiente para reivindicar mais espaço, os espaços são reduzidos e/ou esvaziados dramaticamente. De saída, a incorporação (nos termos em que é buscada) de toda a comunidade é, mesmo abstraindo-se todas as demais restrições, impossível. Jappe (2013, p. 152), por exemplo, sublinha que "um dos aspectos mais ameaçadores do mundo contemporâneo: indivíduos e grupos cada vez mais numerosos se tornam 'supérfluos' visto que 'inúteis'. 'Inúteis' [...] do ponto de vista da valorização do valor".

Nesse sentido, podemos reformular o enunciado de Carcanholo e Baruco (2010), que sustentam que o capitalismo é indiferente a diferenças extraeconômicas e, portanto, pode conviver com a exclusão sistemática de grupos inteiros da população. O enunciado mais preciso, em nosso juízo, traria a afirmação adicional de que, na medida que a exclusão geral é crescente, é funcional à reprodução dessa sociedade que certos grupos se encontrem excluídos a priori do mercado de trabalho, especialmente se tal exclusão for atribuída a causas extraeconômicas.

Assim, há ao menos duas razões para que as reivindicações das pessoas transgêneras assumam contornos anticapitalistas. Em primeiro lugar, porque a indiferença e a funcionalidade mencionadas acima operam como um obstáculo (não absoluto, evidentemente) a avanços no plano subjetivo, i.e. no reconhecimento geral da legitimidade dessas reivindicações. Em segundo lugar,

TrabalhoNecessario - www.uff.br/trabalhonecessario; Ano 15, №28/2017 
porque a incorporação, em qualquer escala relevante é impossível. Diga-se, impossível nesta sociedade; impossível na sociedade em que o trabalho (em geral) e o trabalho produtor de valor (em particular) operam como mediação social central e determinam a forma de sociabilidade acessível a cada indivíduo.

\section{Referências Bibliográficas}

BEAUVOIR, Simone de. O segundo sexo: fatos e mitos. São Paulo: Difusão Europeia do Livro, 1970.

BUTLER, Judith. Gender trouble: Feminism and the Subversion of Identity. Londres: Routledge, 2007.

CARCANHOLO, Marcelo Dias; BARUCO, Grasiela Crisitna da Cunha. As aventuras de Karl Marx contra a pulverização pós-moderna das resistências ao capital. Margem Esquerda, São Paulo, v. 13, p.74-91, jan. 2010.

DUAYER, M.; MEDEIROS, J. L. Marx, estranhamento e emancipação: o caráter subordinado da categoria da exploração na análise marxiana da sociedade do capital. Revista de Economia (Curitiba), v. 34, p. 151-161, 2008.

HARAWAY, Donna J. Simians, cyborgs, and women: the reinvention of nature. Nova York: Routledge, 1991.

JAPPE, A. Crédito à morte: a decomposição do capitalismo e suas críticas. São Paulo: Hedra, 2006.

KOHAN, Néstor. Desafíos actuales de la teoría crítica frente al posmodernismo. In: ENCONTRO NACIONAL DE POLÍTICA SOCIAL, 2007, Vitória, Espírito Santo. Anais do $2^{\circ}$ Encontro Nacional de Política Social. Vitória: Ufes, 2007. p. $1-26$.

KURZ, R. Dinheiro sem valor: linhas gerais para uma transformação da crítica da economia política. Lisboa: Antígona, 2014.

LAWSON, T. Economics and reality. Londres: Routledge, 1997.

LUKÁCS, Gyorgy. Para uma ontologia do ser social I. São Paulo: Boitempo, 2012.

LUKÁCS, Gyorgy. Para uma ontologia do ser social II. São Paulo: Boitempo, 2013.

MARX, Karl. O Capital: livro I. São Paulo: Boitempo, 2013 [1867].

TrabalhoNecessario - www.uff.br/trabalhonecessario; Ano 15, №28/2017 
POSTONE, Moishe. Time, labor, and social domination: A reinterpretation of Marx's critical theory. Cambridge: Cambridge University Press, 2003.

RICARDO, D. Princípios de economia política e tributação. São Paulo: Nova Cultural, 1996 [1817].

Recebido em: 7 de dezembro de 2017. Aprovado em: 9 de janeiro de 2018. Publicado em: 31 de janeiro de 2018. 